\title{
APRENDIZAGEM E COORDENAÇÃO MOTORA: RELAÇÕES INTERDISCIPLINARES PARA O APERFEIÇOAMENTO DA PERFORMANCE PIANÍSTICA
}

\author{
Arele Almeida Vachtchuk ${ }^{2}$ \\ Maria Bernardete Castelan Póvoas ${ }^{3}$
}

\section{Resumo}

A pesquisa "Ação pianística e coordenação motora: relações interdisciplinares" ${ }^{1 "}$ tem como objetivo levantar informações que auxiliem na conscientização do movimento e no aperfeiçoamento da execução pianística. Nesta investigação foram abordados temas relacionados à aprendizagem motora, sendo estabelecidas analogias entre questões de áreas como biomecânica, cinesiologia e ergonomia às discussões técnico-instrumentais. Foram realizadas comparações entre o material estudado e a prática pianística, utilizando-se o recurso técnico-pianístico de flexibilização do movimento, ciclos de movimento, proposto por Póvoas (1999).

Palavras-chave: Aprendizagem Motora; Habilidade Motora; Interdisciplinaridade; Ação Pianística.

\section{Introdução}

O projeto Ação pianística e coordenação motora: relações interdisciplinares tem como proposta o estudo da técnica instrumental baseada na conscientização do movimento aplicado à execução musical no instrumento piano. De acordo com Matthay (1964) técnica é antes uma questão que diz respeito mais à mente do que aos dedos. Nesta pesquisa foram estabelecidas analogias entre questões de áreas como biomecânica, cinesiologia e ergonomia, com vistas às discussões sobre a técnica instrumental. Com base na revisão bibliográfica levantada foram abordados temas relacionados à aprendizagem motora, sendo eles: processos de aprendizagem e classificação de habilidades motoras. Paralelamente, foram feitas comparações entre o material estudado e a prática pianística, utilizando-se o recurso técnicopianístico de flexibilização do movimento proposto por Póvoas (1999), os ciclos de

\footnotetext{
${ }^{1}$ Vinculado ao Projeto de Pesquisa: Ação Pianística e Coordenação Motora: Relações Interdisciplinares - Centro de Artes - UDESC.

2 Arele Almeida Vachtchuk - Bolsista de Pesquisa do Sistema PROBIC - UDESC, aluna do Curso de Bacharelado em piano, CEART/UDESC

3 Profa. Dra. Maria Bernardete Castelan Póvoas, Professora do Depto de Música, CEART/UDESC. Coordenadora do Projeto
} 
movimento $^{2}$. O objetivo principal da presente pesquisa foi coletar informações que auxiliassem no aprimoramento da execução pianística, a qual depende da coordenação de diversos movimentos, buscando-se planejar e alcançar resultados em menos tempo, com o máximo de rendimento com um menor gasto de energia.

\section{Métodos}

No decorrer da pesquisa foram realizadas revisões bibliográficas interdisciplinares, com intuito de aprofundar investigações relacionadas a questões motoras e cognitivas, que são freqüentemente utilizadas na ação pianística. Primeiramente, foram realizadas reuniões semanais onde foram ensinados exercícios de alongamento e relaxamento para serem efetuados antes e nos intervalos de estudo e, também foram discutidos assuntos sobre a importância da conscientização dos movimentos para nossa realização pianística. Isso, na prática, fez com que percebessemos a importância da interação entre pressupostos de diversas áreas para a atividade pianística.

Os bolsistas da presente pesquisa, sob orientação, fizeram uso do princípio de relação impulso-movimento - ciclos de movimento (PÓVOAS, 1999), com a intenção de aprimorar o estudo do piano e por ser possível criar relações aos tipos de movimentos e ao resultado sonoro pretendido. Foram feitas conexões entre pressupostos da técnica pianística e assuntos de áreas como ergonomia, cinesiologia e biomecânica, que focam a utilização de membros responsáveis na realização de movimentos envolvidos na ação pianística e suas contribuições aprimoraram o estudo aqui proposto.

Como auxílio na compreensão e racionalização do movimento em função do aperfeiçoamento de funao na execução musical, destaca-se o estudo sobre aprendizagem motora e sobre conceitos relacionados a este campo, como classificação de habilidades motoras e processos de aprendizagem.

\section{Resultados}

\footnotetext{
${ }^{2}$ Controle do movimento com base em um princípio de relação e regulação do Impulso - Movimento, proposto por Póvoas (1999).
} 


\title{
- Aplicação do Ciclo do Movimento
}

De acordo com Kaplan (1987), movimento é todo corpo ou objeto que se transporta no espaço. Fisiologicamente existem dois tipos básicos de movimento: reflexo e voluntário. A pesquisa tem base no movimento voluntário, onde remete aspectos cognitivos para realizar ações variadas dentro da interpretação pianística. Tendo como princípio a racionalização dos movimentos, subtende-se um aprimoramento nas atividades que antes não eram conscientes. Segundo Póvoas (1999, p. 90),

\begin{abstract}
Durante o treinamento é possível desenvolver uma consciência do ato físico de tocar, relacionando o movimento à imagem e ao resultado sonoro e a capacidade de percepção da posição e movimentos das partes do corpo no espaço por meio do controle cinestésico que permite desenvolver o sentido do toque e o controle sobre o comportamento físico-muscular.
\end{abstract}

Para a concepção de um ciclo de movimento Póvoas (1999) considera dois pontos do movimento que servem como referência, um inicial ( $\mathbf{i}$ ) e outro final ( $\mathbf{f}$ ), que serão percorridos por um gesto, sendo três fases componentes desse processo: fase da impulsão ou apoio inicial, fase de percurso e fase da queda (apoio). Com intuito de diminuir a diferença entre a reação muscular no período de estudo, onde a peça é executada num andamento mais lento do aquele que deverá ocorrer em estágios em que a velocidade de execução da obra é a ideal ou mais próxima desta, os ciclos de movimento devem ser organizados de acordo com o texto musical e o andamento pretendido em sua realização instrumental.

A operacionalização do princípio proposto por Póvoas (1999) inicia-se por uma reflexão analítica para a decodificação do texto musical. Orienta para a adequação de movimentos corporais às questões físico-musculares relacionados aos as pectos técnicoinstrumentais e musicais (design, caráter e sonoridade), objetivando æz organização do movimento, a partir da relação entre uma ação corporal e resultados sonoros. De acordo com Póvoas (1999, p.95):

\footnotetext{
Segundo o princípio, a orientação no sentido lateral de ca da linha indica a movimentação dos segmentos na extensão, do teclado representando o deslocamento na coordenada $\mathrm{x}$; a orientação ascendente ou de scendente das setas orienta o sentido do gesto sobre o teclado com relação `a coordenada y; finalmente, a concavidade ou convexidade do desenho das linhas indicam a movimentação na profundidade da tecla, ou coordenada $\mathrm{z}$.
} 


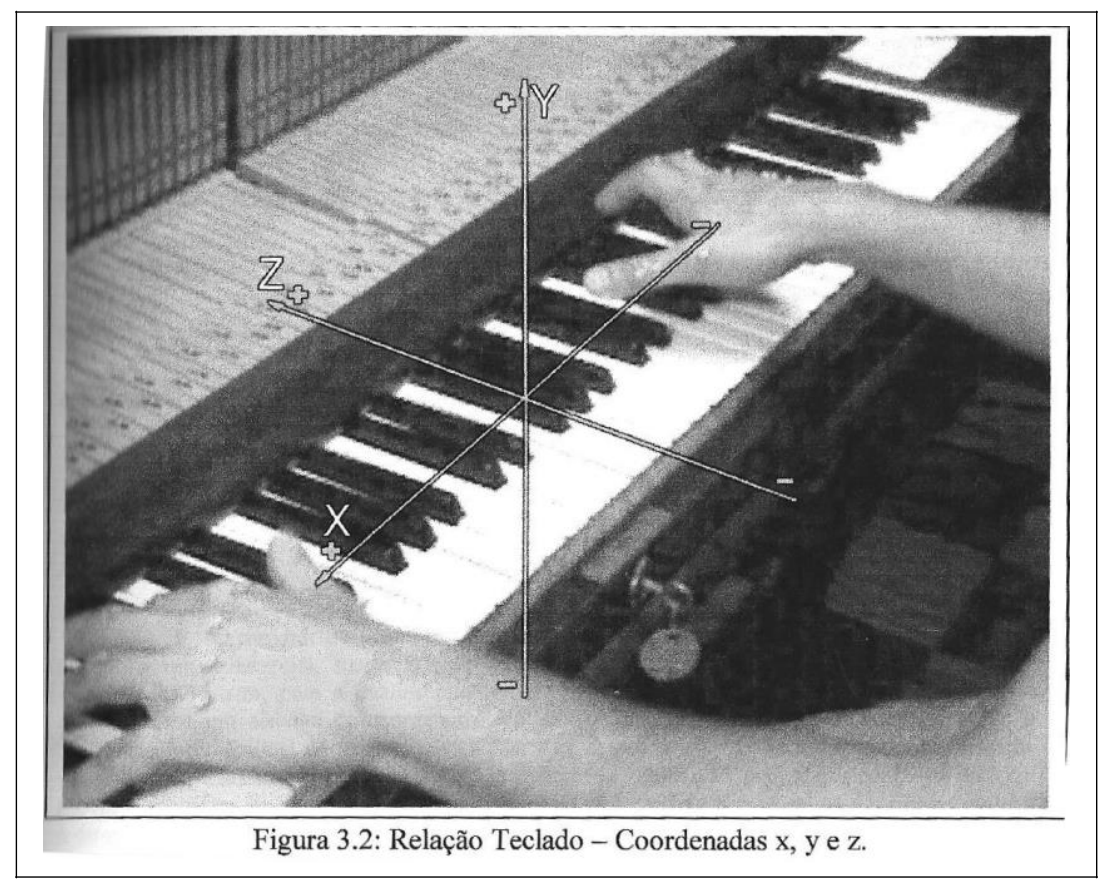

Figura 01- Relação Teclado - Coordenadas x,y e z. Fonte: PÓVOAS, 1999, p.94.

A aplicação do princípio apresentado na Figura 02 pressupõe a realização musical dos trechos iniciando pela movimentação dos segmentos mão, punho e antebraço que devem partir de uma posição mais baixa para mais alta com relação ao teclado. As setas indicam o trajeto que deve ser percorrido explorando-se as coordenadas $\mathrm{x}, \mathrm{y}, \mathrm{z}$, no sentido de uma maior flexibilização do movimento.
i
f $\mathbf{i}$
f $\mathbf{i}$

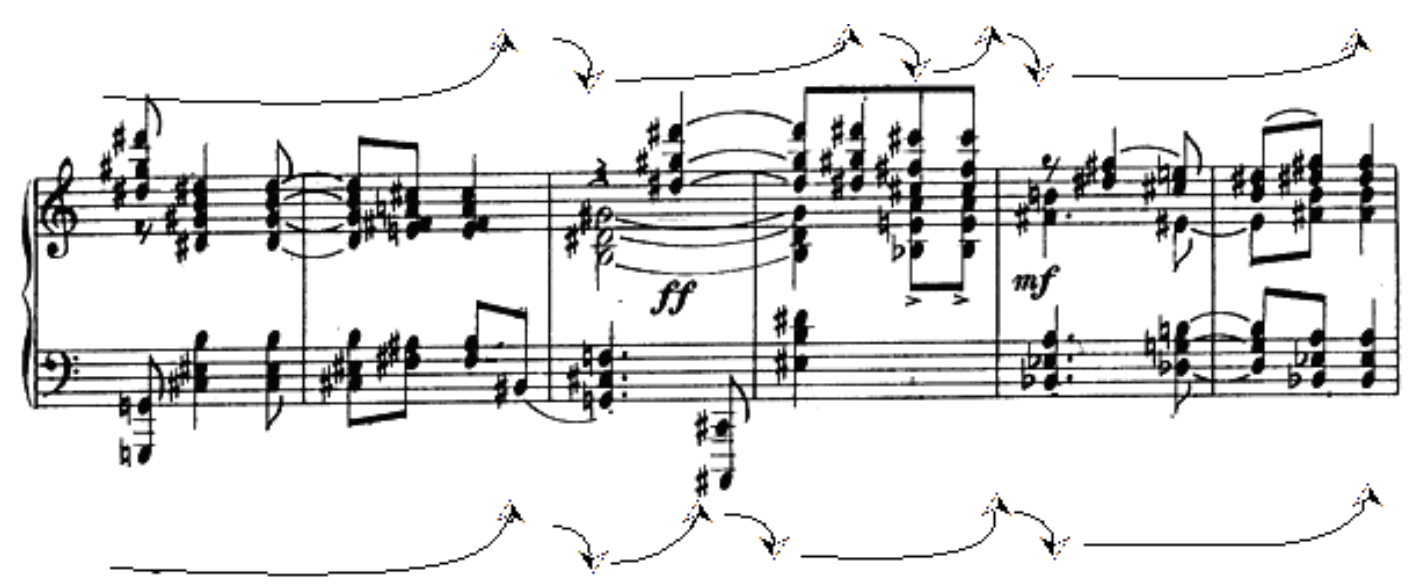

Figura 02: Aplicação do Principio de Relação e Regulação do impulso-movimento. Ponteio de Ernst Mahle (compassos [31] a [36]). Fonte: In Brasilian Composer. Mainz: Schott, s/d, p. 35. 
Segundo Kochevitcky (1967, p. 8 e 9), o movimento em linhas curvas contínuas é mais econômico do que mover-se em linhas angulares retas. Gestos parabólicos e flexíveis permitem um movimento contínuo, com mudanças de trajeto sem interrupções, sendo assim realizado com maior regularidade e menor desgaste físico.

Sendo o princípio anterior aplicado, é importante acrescentar que durante a prática, devem ser escolhidos e empregados os mesmos movimentos (alavanca óssea) que irão ser utilizados durante a execução. (KAPLAN, 1987).

\section{Discussão}

\section{- Processos de Aprendizagem}

Para esta parte da pesquisa e com base nos estudos realizados sobre processos aprendizagem foram selecionados, para um maior aprofundamento, os seguintes tópicos: diferença entre performance e aprendizagem, estabelecimento de metas e algumas das variáveis do desempenho.

Segundo Magill (2000), antes de definir aprendizagem é necessário fazer distinção entre dois termos importantes: desempenho e aprendizagem. Desempenho é o comportamento observável, se refere à execução de uma habilidade num determinado instante e numa determinada situação. Enquanto, aprendizagem, não é um objeto observável, mas sim, processos internos que somente podem ser avaliados através do desempenho da pessoa.

Definição genérica para o termo aprendizagem: uma alteração na capacidade da pessoa em desempenhar uma habilidade, que deve ser inferida como uma melhoria relativamente permanente no desempenho devido à prática ou à experiência (MAGILL, 2000, p.136).

De acordo com Schmidt e Wrisberg (2001) a performance motora é sempre observável e fatores como motivação, foco de atenção, condição física, entre outros, podem influenciá-la. A aprendizagem ocorre através de mudanças em processos internos, podendo ser avaliada por demonstrações de performance relativamente estáveis. O nível de aprendizagem motora de um indivíduo aumenta com a prática, sendo assim, para que o sujeito aprenda as tarefas 
motoras, precisa empenhar-se a essa prática, tendo como resultado, capacidade para produzir a ação desejada. Porém, quando se trata de aprendizagem pode-se questionar se a repetição por si própria auxilia nesse processo. Segundo Kaplan (1887), o movimento é a manifestação periférica de um processo que se origina e é controlado pelo cérebro e pelo sistema nervoso central. Sendo assim, o movimento repetido sem nenhuma intenção pode até ser adquirido, porém com um período de aquisição maior e com muito desgaste.

Para descobrir o caminho que deve ser percorrido é necessário saber qual é o ponto de chegada, desta forma, "um importante pré-requisito para a aprendizagem produtiva é um claro entendimento da meta pretendida pelo aprendiz". (SCHMIDT e WRISBWEG, 2001, p.191). Para atingir-se tal meta, torna-se necessário que fatores físicos e psicológicos que constituem o indivíduo, no caso o pianista, sejam considerados. Dentre esses fatores poderão ser verificados: tempo disponível para a prática do instrumento, qual o seu nível de leitura musical e de consciência do seu próprio corpo, se postura, conformação fisiológica como tamanho das mãos, tipos de toque, entre outros. Com o desenvolvimento no trabalho, o instrumentista deve ter condições de avaliar suas próprias características e saber quais as questões mecânicas a serem aperfeiçoadas.

Schmidt e Wrisberg (2001) sugerem uma abordagem do aprendizado baseado no problema, eles afirmam que, “os aprendizes de hoje devem ser capazes de definir problemas com precisão e separar a informação disponível de que precisam para propor soluções factíveis". (SCHMIDT e WRISBWEG, 2001, p.30). Em segundo lugar, investigar qual a natureza da tarefa a ser realizada, neste caso, a situação a músico-instrumental. A escolha do repertório tem grande influência para a motivação dos estudos; por ser uma prática diária e para direcionar e intensificar o empenho da pessoa para o alcance da meta é importante que condiga com o gosto do pianista. Afirmam os autores que: "Pessoas altamente motivadas dedicam maior esforço à tarefa, são mais conscientes durante as sessões de aprendizagem, além de estarem dispostas a praticar por maiores períodos de tempo". (SCHMIDT e WRISBERG, 2001, p.195). Em um terceiro momento estudar-se-á o contexto-alvo, ou seja, será realizada a tarefa proposta.

São diversas as experiências que devem ser vivenciadas, pois existem variáveis que influenciam na realização músico-instrumental. Por exemplo, executar uma peça em frente ao professor gera um nível de ansiedade diferente daquele quando o indivíduo está em um ambiente sozinho. Por isso é importante que o instrumentista esteja preparado para desempenhar sua atividade em situações distintas. 
Para Magill (2000), com a aprendizagem existe um aumento na capacidade para desempenhar uma ou mais habilidades, porém se o indivíduo irá ou não realizá-la efetivamente, dependerá de certos fatores conhecidos como as variáveis de desempenho. Uma dentre estas variáveis é a ansiedade, definida como "apreensão ou angústia da pessoa sobre incertezas futuras; a percepção de ameaça para si mesmo. Freqüentemente caracterizada pelo elevado nível de ativação”. (SCHMIDT \& WRISBERG, 2001, p. 219). Quando as pessoas sabem que seu desempenho está sendo avaliado, os níveis de ativação e ansiedade aumentam; para amenizar estas variáveis é importante que experiências anteriores tenham sido realizadas em ambientes parecidos com o contexto-alvo em que as tarefas serão efetivadas.

Percebe-se que a aprendizagem motora ocorre cognitivamente e pode ser verificada através da atividade pianística, porém, para uma melhor aprendizagem, é necessário que as metas sejam estabelecidas e que, paulatinamente, se trabalhe em função da eficiência do desempenho.

\section{- Classificação de Habilidades Motoras}

As habilidades podem ser conceituadas como tarefas ou ações que, mais especificamente, têm características voluntárias, podem ser aprendidas e apresentam uma meta ou objetivo. É necessário classificá-las para que sua natureza seja entendida e então sua realização seja facilitada. Schmidt e Wrisberg (2001, p.19) abordam três características utilizadas para classificar tarefas: "a forma como o movimento é organizado; a importância relativa dos elementos motores e cognitivos; o nível da previsibilidade ambiental envolvendo a performance da habilidade".

Dentro da organização do movimento são encontradas habilidades discretas, seriadas e contínuas. Primeiramente, as habilidades discretas têm como característica início e fím bem definidos, são breves em duração e costumam ser simples e objetivas. As habilidades seriadas são para formar ações mais complexas e são constituídas de várias habilidades discretas conectadas em uma seqüência, onde a ordem é crucial para o êxito de sua performance. Estas requerem um tempo mais longo, mesmo assim cada elemento do movimento retém um início e um fim discretos. De acordo com Schmidt e Wrisberg (2001, p.20): 
prática, eles são capazes de combinar os elementos para formar um único e maior elemento, o que permite ao executante controlar toda a ação, quase como se fosse um movimento discreto único.

Como uma segunda característica, são estudadas as habilidades cognitivas e motoras. Em uma habilidade motora a ênfase está na qualidade do movimento a ser realizado, pois subentende-se que o indivíduo já tenha entendido o que deve ser feito. Aqui o desafio proposto é o aperfeiçoamento da técnica para a atividade realizada. No desenvolvimento da habilidade cognitiva o mais importante é a decisão ou estratégia sobre qual movimento efetuar, mais do que a própria natureza do movimento. Para Schmidt e Wrisberg (2001,p.21),

\begin{abstract}
A abordagem mais apropriada para classificar as habilidades, de acordo com esse sistema, é a de considerar o grau com o qual os elementos cognitivos (e perceptivos) (i.e., saber o que fazer) e elementos motores (i.e., realizá-los corretamente) contribuem para o alcance da meta com êxito - o que pode ser a razão pela qual as habilidades motoras são algumas vezes chamadas de 'habilidades psicomotoras' ou habilidades 'percepto-motoras'.
\end{abstract}

Por último, é verificado o nível de previsibilidade ambiental, com isso, são classificadas habilidades abertas e habilidades fechadas. Entre as duas destacamos, para o estudo do piano, a habilidade fechada que é realizada em ambiente estável e permite que os movimentos sejam planejados com antecedência. No caso do piano, o instrumentista durante sua prática/estudo, pode organizar os movimentos com precisão de tempo e sem imprevisibilidades ambientais, como é o caso do exemplo a seguir (Figura 03).

Pesquisas mostram que no estudo do piano as habilidades discretas e seriadas são as que mais ocorrem. Para exemplificar, utilizamos analogias feitas a partir de relações entre esta pesquisa e a minha prática pianística. Assim, tentamos demonstrar como o estudo pode ser muito mais eficiente quando as características da habilidade específica são observadas e então tratadas com especificidade.

O trecho musical mostrado na Figura 03 está organizado em pequenos fragmentos (linha vermelha), delimitados pela obtenção de uma idéia musical menor, por ter caráter objetivo e ter início e final, bem definidos. A linha azul exerce um papel importante, pois mostra a nota seguinte a ser tocada, sendo assim, além de ser estudado o fragmento isolado, o próximo evento, mesmo que não executado, deve ser preparado. Essa também se torna a função da sobreposição de algumas partes das linhas vermelhas, pois a idéia é que, após o estudo isolado, estes fragmentos sejam interligados. Vale acrescentar que no início do estudo 
de cada trecho, a linha destinada à execução dos segmentos direito e esquerdo podem ser executados separadamente. Em uma segunda etapa, o estudo de todo o contexto musical com a união das linhas de ambas as mãos pode ser realizada com mais facilidade.

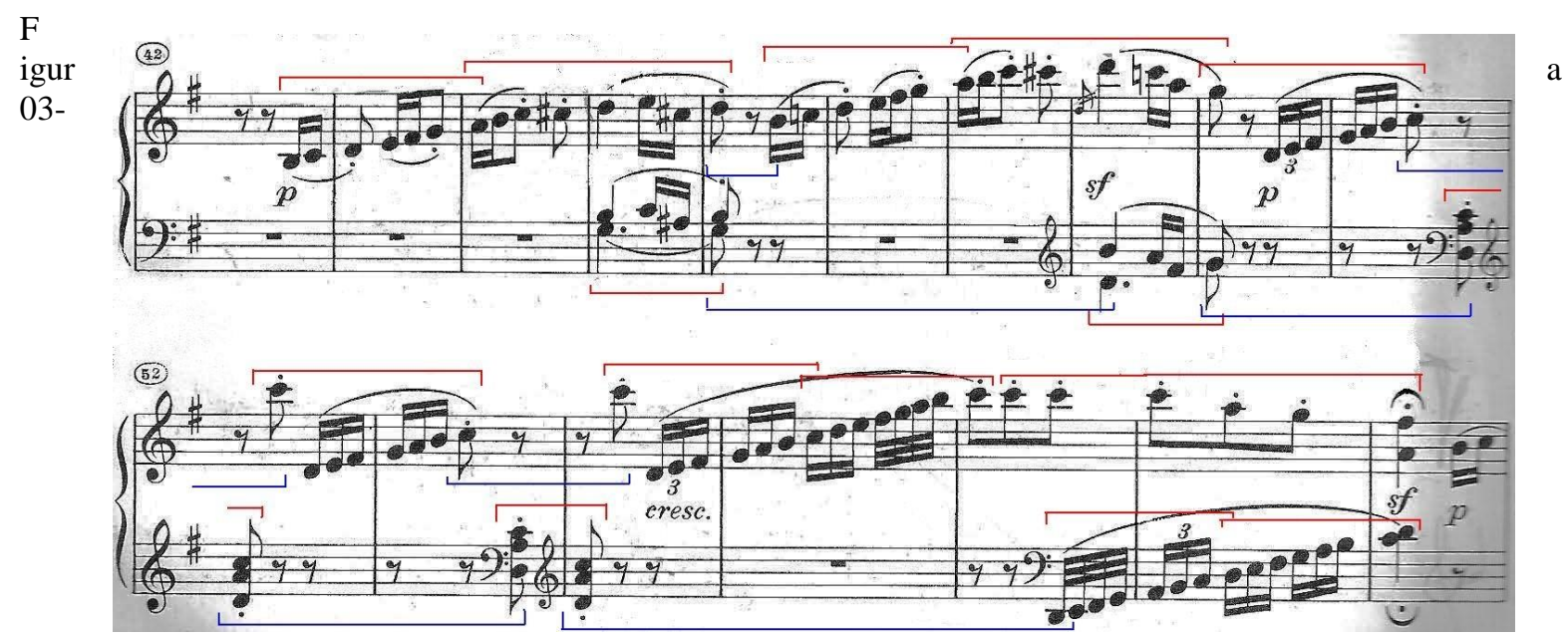

Idéias musicais. Scherzo, terceiro movimento da Sonata Op. 14 n.2 de Beethoven (compassos [42] a [58]). Fonte: BEETHOVEN: München: Henle Verlag, s/d., p. 188.

Como mencionado anteriormente, é essencial que haja uma intenção ou meta para que se realize um movimento com maior eficácia. No caso, por se tratar de uma habilidade psicomotora, é necessário que o instrumentista pense na idéia musical (fraseado, fórmula de compasso, tempos forte e fraco, etc.), nas notas e no dedilhado, nos tipos de movimento (ver princípio proposto por Póvoas, 1999) e quais são as notas de chegada, que ligam um segmento ao outro. Todas essas informações devem ser verificadas antes de iniciar o movimento por si próprio, uma vez que a intenção seja a de estudar conscientemente uma nova situação musical ou peça.

Para Meinel, a meta e o resultado de uma ação são antecipados e determinam a estrutura do ato de movimento' além do que o processo de antecipação baseia-se em experiências existentes, refletindo-se nos resultados da atividade proposta. (MEINEL apud PÓVOAS,1999, p.53).

Todo movimento pensado e antecipado é realizado com mais consistência. Existem diversos tipos de movimentos e situações dentro de um trecho musical e todos podem ser devidamente preparados. Dentro disso vale mencionar os "saltos". No compasso [52] da Figura 03, observamos um exemplo simples de "salto". Esta situação técnico-musical se repete várias vezes no decorrer do desenvolvimento do pianista e, uma vez resolvida, auxiliará 
em todas as situações equivalentes que ocorrerão. Para se resolver o "salto", é proposto uma simplificação da ação diminuindo a distância entre uma nota e outra ou acordes.

No compasso [52] observamos um salto descendente a partir da nota mi para uma nota ré, uma oitava abaixo. Inicialmente, ao invés de estudar o salto, propõe-se realizar a nota ré na mesma oitava do mi, criando uma imagem temporal e sonora de como os eventos devem soar, porém aproximados. Tal estratégia auxilia nosso cérebro a criar referências, uma vez que o piano visualmente é igual em toda sua extensão e obtém apenas uma oitava que se repete por toda a superfície. Sendo assim, o sistema nervoso central, através dessa aproximação, processa informações necessárias. Posteriormente, este esse movimento simplificado pode ser expandido para qualquer distância ao piano.

No estudo deste trecho musical (Figura 03), são verificadas características da habilidade seriada. Por se tratar de uma única música, os fragmentos devem ser combinados para formar uma idéia musical maior, o que permite ao executante controlar toda a ação, quase como se fosse um movimento discreto único. A sequiência em que as partes serão executadas é essencial para a execução da peça. Como auxílio nesse processo, o instrumentista estaria apto a unir diversas pequenas idéias, formando fraseados maiores e alterando a forma de contar os valores (tempo e subdivisões). Para exemplificar, utilizamos novamente a Figura 03, onde a fórmula de compasso é 3/8. Neste caso, ao invés de contar os três tempos, utiliza-se de um tempo maior, considerando-se um ou dois compassos, para assim conceber-se uma imagem sonora maior para, na sequiência e como conseqüência, haver um aumento na velocidade até atingir aquela que o trecho requer.

A orientação para o trabalho instrumental do trecho anterior pode ser aplicada à maior parte de todo o movimento (Scherzo). Ao início do estudo, é possível fragmentar uma parte da música e trabalhar com profundidade cada trecho, buscando-se assim uma aprendizagem mais eficaz e um melhor desempenho quando da realização de trechos maiores e da peça como um todo.

\section{Conclusão}

Através desta pesquisa chegamos à conclusão que todo movimento pensado e calculado pode ser devidamente executado. A organização do movimento, sendo eles flexíveis e parabólicos, auxilia numa maior naturalidade do movimento, o que também gera uma maior 
continuidade do mesmo. Essa organização também possibilita uma minimização de energia, porque somente aqueles movimentos, que realmente são necessários serão utilizados. E por fim a fragmentação de um trecho musical nos auxilia num aprofundamento de pequenas partes, e através das conexões, uma idéia maior pode ser realizada com facilidade. Sendo assim o estudo realizado paulatinamente pode ser muito mais eficiente para a aprendizagem e execução pianística.

\section{REFERÊNCIAS BIBLIOGRÁFICAS}

BETHOVEN, Ludwig Von. Klavier Sonaten, Band I. München: Henle Verlag, p. 188.

KAPLAN, José Alberto. Teoria da Aprendizagem Pianística. Porto Alegre: Editora Movimento, 1987.

KOCHEVITSKY, Gorge. The Art of Piano Playing: a scientific approach. New York: Summy-Birchard, 1967.

MAGILL, Richard A. Aprendizagem Motora. Conceitos e Aplicações. Tradução da $5^{\mathrm{a}}$ ed. Americana. São Paulo: Editora Edgard Blücher, 2000.

MATTHAY, Tobias. The visible and invisible in Pianoforte Technique. London: Oxford University Press, 1964.

PÓVOAS, Maria Bernardete Castelan. Controle de Movimento com Base em um Princípio de Relação e Regulação do Impulso-Movimento: Possíveis Reflexos na Otimização da Ação Pianística. Dissertação de Doutorado. UFRGS, Porto Alegre, 1999.

SCHIMIDT, R. A.; WRISBERG, C. A. Aprendizagem e Performance Motora. Uma abordagem da aprendizagem baseada no problema. $2^{\mathrm{a}}$ ed. Porto Alegre: Editora Artmed, 2001. 